\title{
Multidrug resistance protein 1 protects the choroid plexus epithelium and contributes to the blood-cerebrospinal fluid barrier
}

\author{
Jan Wijnholds, ${ }^{1}$ Elizabeth C.M. de Lange, ${ }^{2}$ George L. Scheffer, ${ }^{3}$ Dirk-Jan van den Berg, ${ }^{2}$ \\ Carla A.A.M. Mol, ${ }^{1}$ Martin van der Valk, ${ }^{4}$ Alfred H. Schinkel, ${ }^{5}$ Rik J. Scheper, ${ }^{3}$ \\ Douwe D. Breimer, ${ }^{2}$ and Piet Borst ${ }^{1}$
}
${ }^{1}$ Division of Molecular Biology and Center for Biomedical Genetics, The Netherlands Cancer Institute, 1066 CX Amsterdam, The Netherlands
${ }^{2}$ Division of Pharmacology, Leiden/Amsterdam Center for Drug Research, 2300 RA Leiden, The Netherlands
${ }^{3}$ Department of Pathology, University Hospital Free University, 1081 HV Amsterdam, The Netherlands
${ }^{4}$ Department of Experimental Animal Pathology, and
${ }^{5}$ Division of Experimental Therapy, The Netherlands Cancer Institute, 1066 CX Amsterdam, The Netherlands
Jan Wijnholds and Elizabeth C.M. de Lange contributed equally to this work.

Address correspondence to: Piet Borst, The Netherlands Cancer Institute, Plesmanlaan 121, 1066 CX Amsterdam, The Netherlands. Phone: 31-20-5122880; Fax: 31-20-6691383; E-mail: pborst@nki.nl.

Received for publication August 26, 1999, and accepted in revised form December 21, 1999.

\begin{abstract}
Multidrug resistance protein 1 (MRP1) is a transporter protein that helps to protect normal cells and tumor cells against the influx of certain xenobiotics. We previously showed that Mrp1 protects against cytotoxic drugs at the testis-blood barrier, the oral epithelium, and the kidney urinary collecting duct tubules. Here, we generated $M r p 1 / M d r 1 a / M d r 1 b$ triple-knockout (TKO) mice, and used them together with $M d r 1 a / M d r 1 b$ double-knockout (DKO) mice to study the contribution of Mrp1 to the tissue distribution and pharmacokinetics of etoposide. We observed increased toxicity in the TKO mice, which accumulated etoposide in brown adipose tissue, colon, salivary gland, heart, and the female urogenital system. Immunohistochemical staining revealed the presence of Mrp1 in the oviduct, uterus, salivary gland, and choroid plexus (CP) epithelium. To explore the transport function of Mrp1 in the CP epithelium, we used TKO and DKO mice cannulated for cerebrospinal fluid (CSF). We show here that the lack of Mrp1 protein causes etoposide levels to increase about 10-fold in the CSF after intravenous administration of the drug. Our results indicate that Mrp1 helps to limit tissue distribution of certain drugs and contributes to the blood-CSF drug-permeability barrier.
\end{abstract}

J. Clin. Invest. 105:279-285 (2000).

\section{Introduction}

Cancer cells overproducing cellular drug extruders may become resistant to a wide spectrum of drugs with different structures or cellular targets. This phenomenon is called multidrug resistance (MDR) (1). Three ATPdependent transmembrane drug transporters - the multidrug resistance gene product MDR1 P-glycoprotein (Pgp) (1), the breast cancer resistance protein (2-4), and multidrug resistance protein 1 (MRP1) (5-9) - can render cells multidrug resistant in vitro. MRP1 is a socalled glutathione-conjugate pump, or multispecific organic anion transporter (10), and is a versatile pump. It can mediate the extrusion of glutathione- $S$ conjugates, glucuronide conjugates, and sulfate conjugates of drugs (10-13); it is the major transporter for endogenous $\mathrm{LTC}_{4}$, an important mediator of the inflammatory response $(11,14)$; and it can even extrude neutral and basic organic compounds if the cell contains normal levels of glutathione (15-18).

To elucidate the physiological functions of the MDR-conferring transporters, mutant mice have been generated lacking Mdr1a Pgp and Mdr1b Pgp (19, 20), or lacking Mrp1 $(14,21)$. Mdr1a Pgp plays an important role in the intestinal epithelium, where it actively excretes xenobiotics absorbed from the intestinal lumen back into the lumen. It thereby limits the entry of Pgp substrates into the body. In addition, Mdr1a Pgp plays an important role in the blood-brain barrier $(19,20,22-24)$. This barrier is primarily formed by the endothelium of the blood capillaries in the brain. The presence of Mdr1a Pgp in the apical (luminal) plasma membranes of these capillary endothelial cells (25) is crucial for the protection of the brain against several xenobiotics entering from the blood (19).

Mrp1-deficient mice lack the main high-affinity glutathione conjugate pump activity in erythrocytes, and cells derived from these mice show increased sensitivity to anti-cancer drugs (14). Mrp1 has important protective roles in the epithelium of the tongue and cheek, the urinary collecting duct epithelium, and the epithelial Sertoli cells in the testicular tubules; we have shown that Mrp1 prevents drug-induced oral mucositis, dia- 
betes insipidus, and infertility (26). In addition, Mrp1deficient mice have an impaired response to arachidonic acid-stimulated inflammation, probably due to the decreased cellular extrusion of $\mathrm{LTC}_{4}$ from leukotriene-synthesizing cells (14).

Monoclonal antibodies against MRP1 $(27,28)$ detect this transport protein in several tissues. Its presence has been demonstrated in the basal plasma membrane of the Sertoli cells (26), in the basolateral membranes of the lung epithelium $(26,29)$, in the liver $(30)$, in the rat choroid plexus (CP) epithelium (31), and in transfected kidney cell lines overproducing human MRP1 (32). Here, we show that Mrp1 is also present in the mouse CP epithelium.

The brain is protected against drugs by 2 drug-permeability barriers: the blood-brain barrier and the blood-cerebrospinal fluid (CSF) barrier. The bloodbrain barrier is formed by the endothelium of the blood capillaries; diffusion of some hydrophobic drugs through this barrier is counteracted by transporters such as Mdr1a Pgp (19, 33). The blood-CSF barrier (34) is formed by the epithelium of the CP (35). Recently, some drug transporters (e.g., organic anion transporter protein 1, MDR1 Pgp, and MRP1) have been postulated to play a drug-transporting role in the $\mathrm{CP}(31,36$, 37). The polarized choroidal epithelium uses active transport mechanisms to extract micronutrients from the blood, and produces and secretes CSF (38). The CP also has an important function in the clearance of metabolic waste products and substrates such as LTC $_{4}$ (39), estradiol 17- $\beta$-D-glucuronide (37), prostaglandins (40), iodide (41), benzylpenicillin (42), cephalosporin (43), zidovudine (44-46), and 2,4,5-trichlorophenoxyacetic acid (47) from the CSF toward the blood.

Using wild-type and Mrp1-deficient mice on an Mdr1a Pgp/Mdr1b Pgp-null background $\left(\mathrm{Mrp1}^{+/+} / \mathrm{Mdr1}^{-/-}\right)$ $M d r 1 b^{-/-}$and $M r p 1^{-1-} / M d r 1 a^{-1-} / M d r 1 b^{-1-}$, referred to as DKO and TKO for double knockout and triple knockout, respectively) we demonstrate here that Mrp1 helps to limit the accumulation of etoposide in brown adipose tissue, colon, salivary gland, heart, and the female urogenital tract. Most importantly, we show that Mrp1 in the $\mathrm{CP}$ protects against high etoposide levels in the CSF, indicating that Mrp1 is a critical component of the blood-CSF drug-permeability barrier. This implies that specific inhibitors of MRP1 and MDR1 Pgp may be used to increase the permeability of the blood-CSF and bloodbrain barriers for anti-cancer or other drugs.

\section{Methods}

Animals. The animals used were Mdr1a- and Mdr1b-

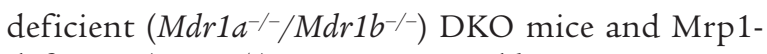
deficient ( $\left.\mathrm{Mrp1}^{-{ }^{--}}\right)$mice, generated by gene targeting in embryonic stem cells as described by Schinkel et al. (19) and Wijnholds et al. (14). Using these mice, $M d r 1 a^{-/-} / M d r 1 b^{-/-} / M_{r p 1} 1^{-/}$triple-knockout (TKO) mice were obtained by crossing. All mice used were on a 50\% 129/Ola, 50\% FVB genetic background. All animals were housed in constant-temperature rooms with a 12-hour-light/12-hour-dark cycle, and had access to a pelleted chow diet (Hope Farms BV, Woerden, The Netherlands) and acidified water ad libitum. Mouse handling and experimental procedures were conducted in accordance with the Netherlands Cancer Institute guidelines for animal care and use.

Drug sensitivity and $\left[{ }^{3} \mathrm{H}\right]$ etoposide distribution in female mice. Etoposide phosphate (Etopophos, $100 \mathrm{mg}$ effective etoposide; Bristol-Myers Squibb Pharmaceutical, Princeton, New Jersey, USA) was dissolved in sterile $0.9 \% \mathrm{NaCl}$ to obtain a stock solution of $4-20 \mathrm{mg} / \mathrm{mL}$. Concentrations were adjusted to inject $5-6.5 \mu \mathrm{L} / \mathrm{g}$ body weight $(20-130 \mathrm{mg} / \mathrm{kg})$ intravenously in the tail vein of female or male mice (11-16 weeks old) that were lightly anesthetized with diethyl ether. Mice were weighed and were observed daily for a period of 2 weeks. Lethal toxicity occurred between days 2 and 13 after injection.

For tissue distribution experiments, tracer $\left[{ }^{3} \mathrm{H}\right]$ etoposide $(475 \mathrm{Ci} / \mathrm{mol})$ was diluted with carrier etoposide (Vepesid; Bristol-Myers Squibb Pharmaceutical) in 5\% (wt/vol) glucose, and was injected into the tail vein at a dose of $1 \mathrm{mg} / \mathrm{kg}$. Tissues from female mice were collected at 4 hours and were processed as described (19).

Histological and immunohistochemical analyses. Histological and immunohistochemical analyses were performed as described $(26,27)$.

Cannulation of lateral brain ventricles for CSF sampling. Female DKO mice and TKO mice 11-16 weeks of age $(25-27 \mathrm{~g})$ were anesthetized by intraperitoneal injection of $6 \mu \mathrm{L}$ Hypnorm/Dormicum/water $(1: 1: 2, \mathrm{vol} / \mathrm{vol} / \mathrm{vol})$ per gram body weight (Hypnorm, Janssen Pharmaceutica, Beerse, Belgium; Dormicum; Roche Pharmaceuticals, Basel, Switzerland). A tail cannula consisting of $15 \mathrm{~cm}$ of polyethylene tubing (outer diameter $0.61 \mathrm{~cm}$, inner diameter $0.28 \mathrm{~cm}$ ) and a $7-\mathrm{cm}$ piece of Zeus tubing (outer diameter $0.48 \mathrm{~mm}$, inner diameter $0.24 \mathrm{~mm}$; Zeus Industrial Products, Orangeburg, South Carolina, USA) was inserted into the tail artery to reach the aorta. The

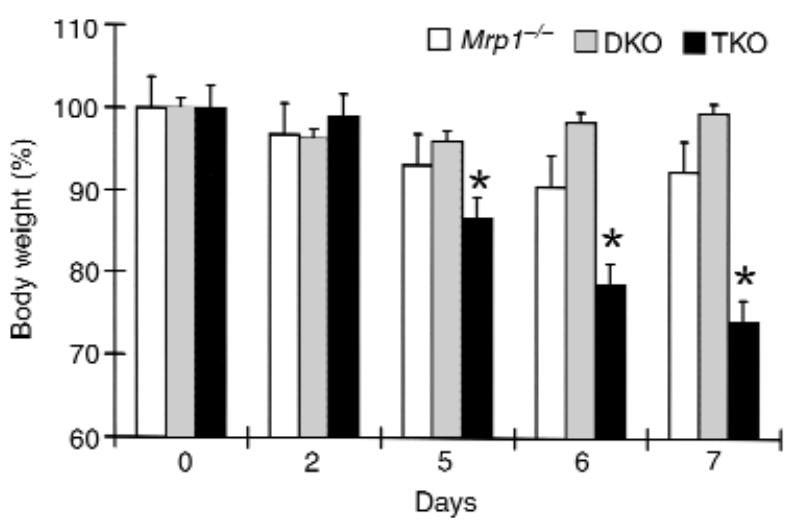

Figure 1

Loss of body weight in mice lacking Mrp1 on a genetic background lacking Mdr1a Pgp and Mdr1b PgP (TKO mice). DKO mice, TKO mice, and $M r p 1^{-1-}$ mice received a single intravenous dose of 60 $\mathrm{mg} / \mathrm{kg}$ Etopophos ${ }^{\circledR}$, and the loss of body weight (\%) was measured over 7 days. ${ }^{*} P<0.001$. 
Table 1

Etopophos ${ }^{\circledR}$ toxicity in male wild-type, $\mathrm{Mrp}^{1^{-/-}}$, DKO, and TKO mice

\begin{tabular}{lcccc}
\hline & \multicolumn{4}{c}{ Survival of mice } \\
$\begin{array}{l}\text { Etopophos }{ }^{\circledR} \text { dose } \\
(\mathrm{mg} / \mathrm{kg})\end{array}$ & Wild type & Mrp $1^{-/-}$ & DKO & TKO \\
20 & & & & \\
40 & - & - & - & $3 / 3^{\mathrm{A}}$ \\
60 & - & - & - & $3 / 3^{\mathrm{A}}$ \\
70 & - & $3 / 3^{\mathrm{A}}$ & - & $1 / 3^{\mathrm{A}}, 3 / 4^{\mathrm{B}}$ \\
80 & - & - & - & $0 / 4^{\mathrm{A}}$ \\
100 & - & $3 / 3^{\mathrm{A}}, 5 / 5^{\mathrm{B}}$ & $4 / 5^{\mathrm{B}}$ & $0 / 3^{\mathrm{A}}$ \\
120 & - & - & $3 / 5^{\mathrm{B}}$ & - \\
& $5 / 5^{\mathrm{B}}$ & - & $0 / 2^{\mathrm{B}}$ & - \\
\hline
\end{tabular}

The number of surviving animals per group at each intravenous Etopophos ${ }^{\circledR}$ dose is shown. The data are from 2 independent experiments ( ${ }^{A}$ and ${ }^{B}$ ), using mice $11-16$ weeks old. For additional toxicity experiments using wild-type and Mrp 1-1mice, see ref. 26. TKO mice show increased sensitivity to Etopophos ${ }^{\circledR}(P<0.01)$.

anesthetized mouse was fixed in a stereotactic apparatus. The skin covering the skull was shaved and disinfected with $70 \%$ ethanol, and then cut crosswise and folded aside. The exposed tissue was locally anesthetized using lidocaine ( $1 \%$ in $0.9 \% \mathrm{NaCl}$ ) and was removed by scraping to expose the skull. The skull was thoroughly cleaned. Two holes were drilled $1.1 \mathrm{~mm}$ apart (laterally) at $0.6 \mathrm{~mm}$ rostral to bregma. A homemade double cannula made of 19-gauge and 23-gauge needles with 4-mm extending tips of fused silica (outer diameter $0.29 \mathrm{~mm}$, inner diameter $0.10 \mathrm{~mm}$; Composite Metal Services Ltd., Worcester, UK) was fixed in a micromanipulator on the stereotactic apparatus. This double cannula was subsequently lowered through the brain tissue into the lateral ventricles to a ventral coordinate at $2.5 \mathrm{~mm}$ to bregma, and fixed first with Cyanolit glue and then with dental cement. The micromanipulator was carefully removed. The mouse was put on a heating pad at $37-39^{\circ} \mathrm{C}$ and was not allowed to awaken. A solution of $145 \mathrm{mM} \mathrm{NaCl}$, $0.6 \mathrm{mM} \mathrm{KCl}, 1.0 \mathrm{mM} \mathrm{MgCl}_{2}, 1.2 \mathrm{mM} \mathrm{CaCl}_{2}$, and $0.2 \mathrm{mM}$ ascorbic acid in $2 \mathrm{mM}$ phosphate buffer ( $\mathrm{pH} 7.4$ ) was perfused into the right lateral ventricle at a flow rate of $0.1 \mu \mathrm{L} / \mathrm{min}$ at a constant rate with a syringe pump. One of the intracerebroventricular cannula lanes was used for infusing the perfusion solution (Baby Bee Hive pump; Bioanalytical Systems Inc., West Lafayette, Indiana, USA), while the other was used to withdraw CSF at the same flow rate into the outlet tubing (home-adjusted Harvard '33' pump; Harvard Apparatus Inc., Holliston, Massachusetts, USA). Once the perfusion and collection had been running constantly for 10 minutes, Etopophos ${ }^{\circledR}(60 \mathrm{mg} / \mathrm{kg})$ was infused through a tail cannula with the aid of a syringe pump $(100 \mu \mathrm{L}$ in 2 minutes). During the 1 hour after the start of Etopophos ${ }^{\circledR}$ administration, CSF was collected through the outlet tubing. The mouse was decapitated and blood and brain were collected. Blood was centrifuged for 10 minutes at $2,000 \mathrm{~g}$ to obtain plasma. CSF, brain tissue, and plasma were stored at $-30^{\circ} \mathrm{C}$ pending analysis.

Analysis of etoposide in plasma, CSF, and brain tissue. After gently thawing, the CSF sample was introduced into an
HPLC system that consisted of a Spherisorb C18 column $(100 \mathrm{~mm} \times 0.8 \mathrm{~mm}$ inner diameter, $5 \mu \mathrm{m}$ particle diameter; Capital HPLC Ltd., Broxburn, UK) using a solvent system of $50 \mathrm{mM}$ sodium acetate buffer with 50 $\mu \mathrm{M}$ EDTA (pH 3.8) and acetonitril (3.8:1 vol/vol) at a flow rate of $40 \mu \mathrm{L} / \mathrm{min}$ (48).

Plasma was diluted with phosphate buffer $(50 \mathrm{mM}$ at $\mathrm{pH}$ 6.0), and brain tissue was homogenized with a Polytron ( $0.2 \mathrm{~g}$ tissue/ $\mathrm{mL}$ phosphate buffer). Etoposide in diluted plasma and homogenized brain tissue was extracted with diethyl ether and dichloromethane (2:1, $\mathrm{vol} / \mathrm{vol}$ ), and then separated on an Econosil C18 column $(250 \mathrm{~mm} \times 4.6 \mathrm{~mm}$ inner diameter, $10 \mu \mathrm{m}$ particle diameter; Alltech Associates Inc., Deerfield, Illinois, USA) using a solvent system of $50 \mathrm{mM}$ sodium acetate with 50 $\mu \mathrm{M} \operatorname{EDTA}(\mathrm{pH} 3.8)$ and acetonitril $(2: 1, \mathrm{vol} / \mathrm{vol})$ at a flow rate of $1.1 \mathrm{~mL} / \mathrm{min}$ (49). Detection was performed electrochemically $(\Delta \mathrm{V}=900 \mathrm{mV})$ using a glassy carbon working electrode (Decade; Antec Leyden BV, Zoeterwoude, The Netherlands). The system was set at $40^{\circ} \mathrm{C}$.

Statistical evaluation. The results are presented as mean \pm SE. The difference between groups was evaluated with the unpaired, 2-tailed Student's $t$ test.

\section{Results}

Altered drug sensitivity in mice lacking Mrp1 on an Mdr1a/Mdr1b-null genetic background. We have previously shown that Mrp1 deficiency renders mice hypersensitive to etoposide or its water-soluble derivative, etoposide phosphate $\left(\right.$ Etopophos $\left.^{\circledR}\right)(14,26)$. Because etoposide is also transported by Mdr1-type Pgps, we crossed $M r p 1^{-/-}$mice with DKO Mdr1 $a^{-/-} / M d r 1 b^{-/-}$mice to obtain TKO Mrp1 $1^{-/-} / M d r 1 a^{-/-} / M d r 1 b^{-/-}$mice. No differences in health, life span, or fertility were observed among TKO, DKO, Mrp1 $1^{-/}$, or wild-type mice in our animal facility. The TKO mice are more sensitive to etoposide than are $\mathrm{DKO}$ and $\mathrm{Mrp1}^{1^{-/}}$mice; all 3 of those groups are more sensitive than are wild-type mice (Tables 1 and 2). Seven days after a single intravenous $60 \mathrm{mg} / \mathrm{kg}$ dose of Etopophos ${ }^{\circledR}$, female $M r p 1^{-/-}$mice $(n=$ 5) retained $92.3 \pm 3.8 \%$ of their body weight $(24.7 \pm 1.1$ $\mathrm{g}$ at day 0$)$ and DKO mice $(n=5)$ retained $99.5 \pm 1.2 \%$ of their body weight $(27.8 \pm 0.9 \mathrm{~g}$ at day 0$)$, whereas female

\section{Table 2}

Etopophos ${ }^{\circledR}$ toxicity in female wild-type, $\mathrm{Mrp}^{1--}$, DKO, and TKO mice

\begin{tabular}{lcccc}
\hline & \multicolumn{4}{c}{ Survival of mice } \\
$\begin{array}{lcccc}\text { Etopophos }{ }^{\circledR} \text { dose } \\
(\mathrm{mg} / \mathrm{kg})\end{array}$ & Wild type & $M r p 1^{-/-}$ & DKO & TKO \\
30 & & - & - & $3 / 3$ \\
50 & - & - & - & $3 / 3$ \\
70 & - & $3 / 3$ & $3 / 3$ & $0 / 3$ \\
90 & - & $3 / 3$ & $1 / 3$ & - \\
110 & - & $0 / 3$ & $0 / 3$ & - \\
130 & $3 / 3$ & - & - & -
\end{tabular}

The number of surviving animals per group at each intravenous Etopophos ${ }^{\circledR}$ dose is shown. Mice used were 11-13 weeks old. TKO mice show increased sensitivity to Etopophos ${ }^{\circledR}(P<0.01)$. 
TKO mice $(n=5)$ retained $74.1 \pm 2.6 \%(P<0.01)$ of their body weight $(26.5 \pm 0.7 \mathrm{~g}$ at day 0 ) (Figure 1 ).

Except for their weight loss, the drug-treated TKO mice showed no clear gross abnormalities. Microscopic analysis at day 7 of TKO, DKO, and $M r p 1^{-1-}$ tissues from mice treated with $60 \mathrm{mg} / \mathrm{kg}$ Etopophos ${ }^{\circledR}$ showed a disruption of the epithelial layer of the tongue and cheek only in the TKO mouse tissue (all TKO mice were thus affected). Inflammation of the tongue epithelium was detected in 4 out of 5 TKO animals (results not shown). The defects were similar to those observed in Mrp1-deficient mice after higher drug doses (26). Analysis of the colon of mice treated with $50-60 \mathrm{mg} / \mathrm{kg}$ Etopophos ${ }^{\circledR}$ showed crypt colitis (5 of 12 TKO mice; 1 of 11 DKO mice) (data not shown). The increase in gut damage to TKO mice suggests that Mrp1 contributes to the protection of the colon. Except for sporadic signs of inflammation in the stomach (in 3 of 5 mice), and a degeneration of the oocytes in the ovary (in 2 of 5 mice), an extensive histopathological examination revealed no further abnormalities in other tissues (data not shown) of the TKO mice. degeneration (9 of 12 TKO mice; 3 of 11 DKO mice) and

We previously found that Mrp1-deficient mice, when treated with a dose of $100 \mathrm{mg}$ Etopophos ${ }^{\circledR}$ per kg body weight, developed diabetes insipidus, demonstrated by the overproduction of dilute urine (26). At close to the maximal drug dose tolerated by the TKO mice in metabolic cages $(50 \mathrm{mg} / \mathrm{kg})$, water intake, urine production (DKO, $1.7 \pm 0.5 \mathrm{~mL}$ per 48 hours; TKO, $1.3 \pm 0.3 \mathrm{~mL}$ per 48 hours), food consumption, and feces production did not differ between DKO and TKO mice. No differences were detected 7 days after drug administration in plasma sodium, urea, creatinine, or protein levels. The number of leukocytes was reduced in TKO mice (DKO, $\left.[13.6 \pm 1.5] \times 10^{9} / \mathrm{L} ; \mathrm{TKO},[3.0 \pm 1.2] \times 10^{9} / \mathrm{L} ; P<0.01\right)$, whereas hemoglobin, hematocrit, and the number of thrombocytes did not differ between DKO mice and TKO mice (data not shown).

Altered drug tissue distribution in mice lacking Mrp1. Although Mrp1 is a ubiquitous protein present in several epithelia $(26,27,29,31)$, our previous etoposide tissue distribution experiments did not show a significant increase in the accumulation of etoposide in Mrp1-deficient tissues (14). This negative result could be explained by redundancy of etoposide transporters; obvious candidates for the
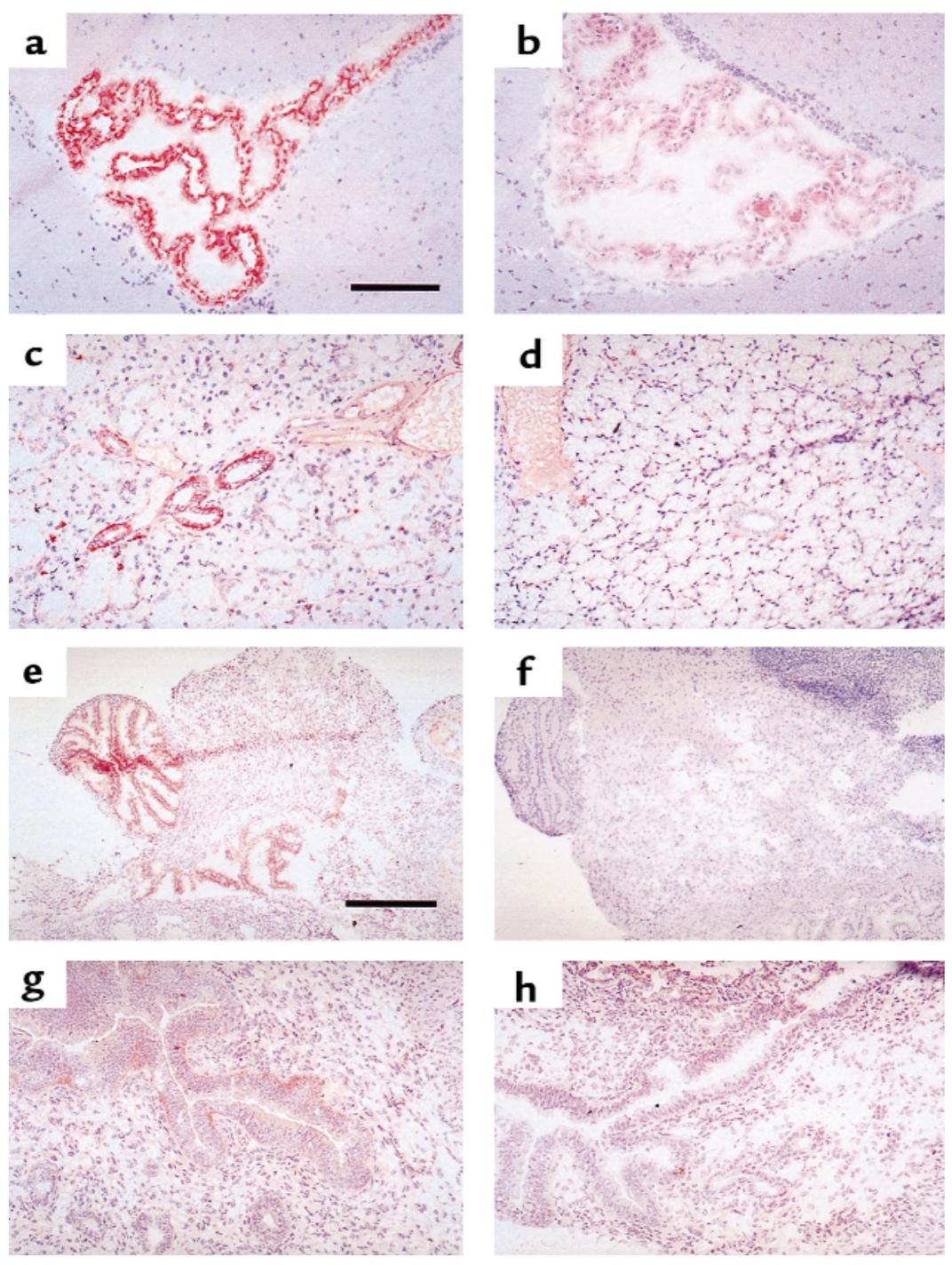
redundant transporters are the Mdr1type Pgps. To test whether Mrp1 can contribute to etoposide cellular clearing in vivo, we administered $1 \mathrm{mg} / \mathrm{kg}$ of radiolabeled etoposide intravenously to DKO mice and TKO mice, and determined the tissue distribution of total radioactivity 4 hours after injection. Table 3 shows that the etoposide plasma levels of DKO and TKO mice were comparable, indicating that Mrp1 does not significantly contribute to the renal, liver, or intestinal clearance of etoposide as was observed for Mdr1-type Pgps $(19,20)$. In the TKO mice, however, we observed increased etoposide accumulation in brown adipose (2.7-fold), colon (2.3-fold), urogenital tract (1.5-fold), salivary gland (1.4-fold), and heart (1.3-fold) tissues $(P<0.05)$; no significant accumulation was detected in brain, liver, kidney, or

\section{Figure 2}

Mrp1 staining of frozen sections of wild-type and Mrp1-deficient tissues using monoclonal antibody MRPr1. Sections were counterstained with hematoxylin. Wild-type (a, c, e, g) and Mrp1deficient mice ( $\mathbf{b}, \mathbf{d}, \mathbf{f}, \mathbf{h})$. ( $\mathbf{a}$ and $\mathbf{b}$ ) Sections of the $C P$ showing Mrp1 staining in the CP epithelium (a). (c and d) Sections of the salivary gland. (e and $\mathbf{f}$ ) Sections of the oviduct. ( $\mathbf{g}$ and $\mathbf{h}$ ) Sections of the uterus. Bar in a represents $100 \mu \mathrm{m}$ and applies to $\mathbf{a}-\mathbf{d}, \mathbf{g}$ and $\mathbf{h}$. Bar in e represents $200 \mu \mathrm{m}$ and applies to $\mathbf{e}$ and $\mathbf{f}$. 

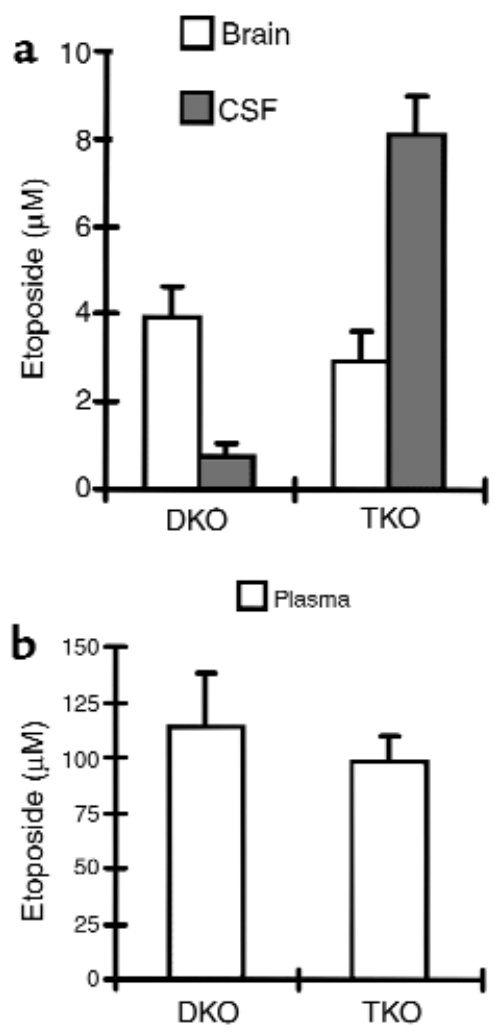

\section{Figure 3}

Increased accumulation of etoposide into the CSF of mice lacking Mrp1 (TKO mice) compared with mice containing Mrp1 (DKO mice). Brain vesicles were cannulated and then perfused with artificial CSF. Etopophos ${ }^{\circledR}(60 \mathrm{mg} / \mathrm{kg})$ was administered via a tail vein; CSF was collected for 1 hour after drug administration, and the etoposide concentration was determined. (a) The TKO mice $(n=5)$ accumulated 10 -fold more etoposide in the CSF than did the DKO mice $(n=4)$ $(8.1 \pm 0.9 \mu \mathrm{M}$ and $0.8 \pm 0.3 \mu \mathrm{M}$, respectively; $P<0.001)$, whereas levels in total brain $(3.9 \pm 0.7 \mu \mathrm{mol} / \mathrm{kg}[n=5]$ and $2.9 \pm 0.7 \mu \mathrm{mol} / \mathrm{kg}[n$ $=4]$, TKO and DKO mice, respectively) did not differ significantly 1 hour after drug administration. (b) Etoposide levels in plasma (98 \pm $12 \mu \mathrm{M}[n=5]$ and $114 \pm 24 \mu \mathrm{M}[n=4]$, TKO and DKO mice, respectively) did not differ significantly 1 hour after drug administration.

other tissues. The observed altered distribution of etoposide in some tissues (with no differences in plasma levels) indicates that Mrp1 contributes to the protection against drugs of a limited set of tissues or cells. The absence of Mrp1 in the basolateral epithelia lining the lumina of some of these tissues (e.g., salivary gland, oviduct, or uterus) could lead to reduced active clearance of drugs from such epithelia to the interstitial fluid and toward the blood as proposed previously (26).

Mrp1 in salivary gland, uterus, oviduct, and CP. To correlate the altered drug distribution with Mrp1 protein location, we stained tissue sections from wild-type mice with the monoclonal antibody MRPr1 (27). As controls, we used mice lacking Mrp1, and isotype-matched control antibodies. We found Mrp1 in the intercalated ducts of the salivary gland, and in the oviduct and uterus (Figure 2, c, e, and g). Sections through the brain showed no staining for Mrp1 in the endothelium of the blood cap- illaries, but immunostaining was abundant in the epithelium of the $\mathrm{CP}$ (Figure 2a). In rat $\mathrm{CP}$ epithelium, staining for Mrp1 protein $(31,37)$ has been reported as well. Mrp1 protein levels were below the detection level in brown adipose tissue, colon, and heart (data not shown). The unexpected lack of immunostaining for Mrp1 in these tissues may be due to the homogeneous distribution of low levels of Mrp1. In previous experiments we showed that Mrp1 is present in heart (14) using Western blots. Using the MRPr1 monoclonal antibody, Peng et al. detected mouse Mrp1 in all colon cells lining the crypt-villus axis, mainly in their basolateral membranes (50). Immunostaining has shown MRP1 to be present in the myocardium of the human heart as well as in the epithelium of the human colon (27).

Mrp1 in the CP limits the entry of drugs into the CSF. The presence of Mrp1 in the CP prompted us to test the possibility that Mrp1 contributes to the transport of drugs at the blood-CSF barrier. Mrp1 is known to route to the basolateral membranes in all epithelia analyzed $(26,32)$, including the rat $\mathrm{CP}$ epithelium (31). If Mrp1 contributes to the drug-permeability barrier between blood and CSF, we would anticipate that Mrp1 transports drugs specifically from the CP toward the blood. To test this hypothesis, we compared the accumulation of etoposide in the CSF of DKO mice and TKO mice. This allowed us to avoid the complicating contribution of Mdr1a Pgp, which is present in the brain capillaries (20) and is reported to be present in the apical membrane of the CP epithelium (31). We chose etoposide as a model substrate because it is clinically relevant and is the best (anti-cancer) drug substrate reported for Mrp1. We preferred to use etoposide as the substrate because the best substrates reported - e.g., the physiological substrate LTC $_{4}$ and the test substance $S$-(2,4-dinitrophenyl)-glutathione - are hydrophilic and are unlikely to enter the $\mathrm{CP}$ epithelium. Cannulas were inserted into the left and right lateral brain ventricles adjacent to the $\mathrm{CP}$, and artificial CSF was slowly perfused at a rate of $0.1 \mu \mathrm{L} / \mathrm{min}$ through the brain lateral ventricles. Etopophos ${ }^{\circledR}(60$ $\mathrm{mg} / \mathrm{kg}$ ) was administered into a tail artery, and CSF was collected for a period of 1 hour. We found that the TKO mice accumulated 10-fold more etoposide in the CSF than did the DKO mice $(P<0.001)$, whereas levels in total brain and plasma did not differ 1 hour after drug administration (Figure 3, $a$ and $b$ ). These results show the potential importance of Mrp1 at the blood-CSF barrier in determining drug levels in the CSF.

\section{Discussion}

Our results indicate that Mrp1 helps to prevent the accumulation of etoposide in vivo, especially in epithelial tissues lining lumina. For some tissues, this protection by Mrp1 is considerable - for example in the $\mathrm{CP}$, as we show in this report. This is also the case in the oral epithelium, the Sertoli cells in the testicular tubules, the urinary collecting duct cells, and white blood cells, as shown previously (26). The protection is significant but small in brown adipose tissue, colon, 
Table 3

Tissue levels of radioactivity in DKO and TKO mice 4 hours after intravenous injection of $\left[{ }^{3} \mathrm{H}\right]$ etoposide $(1 \mathrm{mg} / \mathrm{kg})$

\begin{tabular}{lccc}
\hline Tissue & DKO & TKO & $\begin{array}{c}\text { Ratio } \\
\text { (TKO/DKO) }\end{array}$ \\
& & & $2.7^{\mathrm{A}}$ \\
Brown adipose & $55 \pm 10$ & $147 \pm 38$ & $2.3^{\mathrm{A}}$ \\
Colon & $1,923 \pm 476$ & $4,330 \pm 673$ & 1.7 \\
Small intestine & $1,754 \pm 301$ & $2,936 \pm 863$ & 1.6 \\
Liver & $253 \pm 38$ & $395 \pm 111$ & $1.5^{\mathrm{A}}$ \\
Urogenital tract & $143 \pm 18$ & $211 \pm 22$ & $1.4^{\mathrm{A}}$ \\
Salivary gland & $91 \pm 7$ & $123 \pm 10$ & $1.3^{\mathrm{A}}$ \\
Heart & $85 \pm 6$ & $113 \pm 9$ & 1.2 \\
Stomach & $196 \pm 16$ & $228 \pm 33$ & 1.1 \\
Brain & $83 \pm 7$ & $89 \pm 8$ & 1.1 \\
Muscle & $96 \pm 15$ & $105 \pm 8$ & 1.1 \\
Kidney & $154 \pm 17$ & $167 \pm 23$ & 1.1 \\
Lung & $126 \pm 16$ & $143 \pm 14$ & 0.1 \\
Thymus & $83 \pm 14$ & $88 \pm 15$ & 0.8 \\
Pancreas & $204 \pm 36$ & $172 \pm 19$ & 0.6 \\
Cecum & $7,987 \pm 1,563$ & $6,728 \pm 1,003$ & 1.0 \\
Gall bladder & $230,347 \pm 36,032$ & $129,733 \pm 33,919$ & \\
Plasma & $355 \pm 11$ & $357 \pm 12$ & \\
\cline { 2 - 4 } & & &
\end{tabular}

Results are expressed as mean $\pm \mathrm{SE}$ in $\mathrm{ng} / \mathrm{g}$ tissue ( $\left[{ }^{3} \mathrm{H}\right]$ etoposide equivalent) In 3 independent experiments using weight-matched female mice, 3 mice (of 9 total) were analyzed in each group. ${ }^{A} P<0.05$.

salivary gland, heart, and urogenital tract, as demonstrated by the lack of an observed altered drug distribution in the presence of Mdr1-type Pgps (14).

Most importantly, our experiments provide new information on the physiological function of Mrp1 in the CP. Rao et al. (31) recently showed that enriched membrane fractions of human, rat, and mouse CP contain Mrp1, and that the Mrp1 band on Western blots is missing in CP from $\mathrm{Mrp}^{-/-}$mice. Staining with the anti-Mrp1 antibody was confined to epithelial cells, and mainly the basolateral part of the cells was stained. In cultured rat CP epithelial cells, most of the Mrp1 was present in a vesicular compartment (31). Inhibition of Mrp1 with the LTDy-receptor antagonist and the Mrp1 inhibitor MK-571 increased accumulation of Tcsestamibi (an Mrp1 substrate) by 2-fold in these cells, but did not inhibit transport of Tc-sestamibi through the cell monolayer. Our experiments on the accumulation of etoposide in CSF of DKO mice and TKO mice show that mouse Mrp1 in the CP effectively prevents the entry of etoposide from the blood into the CSF. This proves that the CP epithelium containing Mrp1 acts in vivo as a barrier for certain drugs coming from the blood. Other etoposide cellular efflux pumps (e.g., Mdr1 Pgps) are present in the CP epithelium. Interestingly, Mdr1 Pgps are localized just below the apical plasma membrane, which is compatible with a role in limiting the uptake of substrates from the CSF and contributing to the passage of substrates across the blood-CSF barrier (31).

The blood-brain and blood-CSF drug barriers limit the availability of drugs for the brain by preventing the entry of drugs. Specific inhibitors of MDR1 Pgp, MRP1, or both may be useful in increasing the area under the drug concentration-time curve in CSF, in order to expose brain tumors to a higher dose of anti-cancer drugs. These inhibitors should allow not only more rapid entry of drugs, but also longer retention of drugs directly administered into the CSF. We expect this to work for all anti-cancer drugs commonly transported by MDR1 PgP and MRP1, such as the anthracyclines, Vinca alkaloids, and the epipodophyllotoxins (1, 6-9).

The increased accumulation of etoposide in colon tissue of drug-treated TKO mice is interesting, because high-dose drug treatment may disrupt the normal function of the colonic epithelium (51). This epithelium has an important function in the reabsorption of water from the stool, and drug-induced damage may contribute to dehydration and body weight loss. It is possible that the observed increased frequency of colitis in drug-treated Mrp1-deficient mice is related to the genetic background of our DKO and TKO mice. It has been reported that some $\mathrm{Mdr1a-deficient} \mathrm{mice} \mathrm{(on} \mathrm{an}$ FVB genetic background) are susceptible to development of a severe spontaneous intestinal inflammation with pathology similar to that of human inflammatory bowel disease (52), whereas this has not yet been observed in any of the deficient mice generated and bred in this institute $(19,20)$.

The increased accumulation of etoposide in brown adipose tissue of drug-treated TKO mice indicates a protective function for Mrp1. However, we could not detect Mrp1 protein in brown adipose tissue. The increased accumulation of etoposide after its intravenous administration may be caused by the drug-clearing activity of Mrp1 present at low levels. Tissue-level concentrations of drugs taken up by passive diffusion are determined by the partition ratio and the perfusion rate, however, and these may differ between TKO and DKO mice. Damage or disturbance of the normal function of brown adipose cells may disturb body temperature regulation and contribute to weight loss. The increased accumulation of etoposide in the female urogenital system may lead to a degeneration of oocytes, as was observed for some of the drug-treated TKO animals. The increased accumulation of etoposide in the salivary glands may result in abnormal function of this epithelium, such as an overproduction of mucus as has been reported (14).

In conclusion, these results indicate that at least 2 drug-transporter proteins (MDR1 Pgp and MRP1 in humans) may affect the tissue distribution and pharmacokinetics of an anti-cancer drug such as etoposide.

\section{Acknowledgments}

We thank our colleagues Zsolt Holló and Tohru Saeki for critical advice on the manuscript, and A.J. Schrauwers for biotechnical assistance. This work was supported in part by grants from the Dutch Cancer Society.

\footnotetext{
1. Gottesman, M.M., Hrycyna, C.A., Schoenlein, P.V., Germann, U.A., and Pastan, I. 1995. Genetic analysis of the multidrug transporter. Annu. Rev. Genet. 29:607-649.

2. Doyle, R.A., et al. 1998. A multidrug resistance transporter from human
} 
MCF-7 breast cancer cells. Proc. Natl. Acad. Sci. USA. 95:15665-15670.

3. Allikmets, R., Schriml, L.M., Hutchinson, A., Romano-Spica, V., and Dean, M. 1998. A human placenta-specific ATP-binding cassette gene (ABCP) on chromosome $4 \mathrm{q} 22$ that is involved in multidrug resistance. Cancer Res. 58:5337-5339.

4. Miyake, K., et al. 1999. Molecular cloning of cDNAs which are highly overexpressed in mitoxantrone-resistant cells: demonstration of homology to ABC transport genes. Cancer Res. 59:8-13.

5. Keppler, D., Leier, I., Jedlitschky, G., and König, J. 1998. ATP-dependent transport of glutathione S-conjugates by the multidrug resistance protein MRP1 and its apical isoform MRP2. Chem. Biol. Interact. 111-112:153-161.

6. Cole, S.P., and Deeley, R.G. 1998. Multidrug resistance mediated by the ATP-binding cassette transporter protein MRP. Bioessays. 20:931-940.

7. Cole, S.P.C., et al. 1992. Overexpression of a transporter gene in a multidrug-resistant human lung cancer cell line. Science. 258:1650-1654.

8. Zaman, G.J.R., et al. 1994. The human multidrug resistance-associated protein MRP is a plasma membrane drug-efflux pump. Proc. Natl. Acad. Sci. USA. 91:8822-8826.

9. Cole, S.P.C., et al. 1994. Pharmacological characterization of multidrug resistant MRP-transfected human tumor cells. Cancer Res. 54:5902-5910.

10. Ishikawa, T., Li, Z.S., Lu, Y.P., and Rea, P.A. 1997. The GS-X pump in plant, yeast, and animal cells: structure, function, and gene expression. Biosci. Rep. 17:189-207.

11. Leier, I., et al. 1994. The MRP gene encodes and ATP-dependent export pump for leukotriene $\mathrm{C}_{4}$ and structurally related conjugates. J. Biol. Chem. 269:27807-27810.

12. Jedlitschky, G., et al. 1996. Transport of glutathione, glucuronate, and sulfate conjugates by the $M R P$ gene-encoded conjugate export pump. Cancer Res. 56:988-994.

13. Müller, M., et al. 1994. Overexpression of the gene encoding the multidrug resistance associated protein results in increased ATP-dependent glutathione S-conjugate transport. Proc. Natl. Acad. Sci. USA. 91:13033-13037.

14. Wijnholds, J., et al. 1997. Increased sensitivity to anticancer drugs and decreased inflammatory response in mice lacking the multidrug resistance-associated protein. Nat. Med. 3:1275-1279.

15. Zaman, G.J.R., et al. 1995. Role of glutathione in the export of compounds from cells by the multidrug-resistance-associated protein. Proc. Natl. Acad. Sci. USA. 92:7690-7694.

16. Loe, D.W., Deeley, R.G., and Cole, S.P. 1998. Characterization of vincristine transport by the $\mathrm{M}(\mathrm{r}) 190,000$ multidrug resistance protein (MRP): evidence for cotransport with reduced glutathione. Cancer Res. 58:5130-5136.

17. Renes, J., de Vries, E.G., Nienhuis, E.F., Jansen, P.L., and Müller, M. 1999. ATP- and glutathione-dependent transport of chemotherapeutic drugs by the multidrug resistance protein MRP1. Br. J. Pharmacol. 126:681-688

18. Rappa, G., Lorico, A., Flavell, R.A., and Sartorelli, A.C. 1997. Evidence that the multidrug resistance protein (MRP) functions as a co-transporter of glutathione and natural product toxins. Cancer Res. 57:5232-5237.

19. Schinkel, A.H., et al. 1997. Normal viability and altered pharmacokinetics in mice lacking Mdr1-type (drug-transporting) P-glycoproteins. Proc. Natl. Acad. Sci. USA. 94:4028-4033.

20. Schinkel, A.H., et al. 1994. Disruption of the mouse Mdr1a P-glycoprotein gene leads to a deficiency in the blood-brain barrier and to increased sensitivity to drugs. Cell. 77:491-502.

21. Lorico, A., et al. 1997. Disruption of the murine MRP (Multidrug Resistance Protein) gene leads to increased sensitivity to etoposide (VP-16) and increased levels of glutathione. Cancer Res. 57:5238-5242.

22. Sparreboom, A., et al. 1997. Limited oral bioavailability and active epithelial excretion of paclitaxel (taxol) caused by P-glycoprotein in the intestine. Proc. Natl. Acad. Sci. USA. 94:2031-2035.

23. de Lange, E.C., de Bock, G., Schinkel, A.H., de Boer, A.G., and Breimer, D.D. 1998. BBB transport and P-glycoprotein functionality using MDR1A (-/-) and wild-type mice. Total brain versus microdialysis concentration profiles of rhodamine-123. Pharm. Res. 15:1657-1665.

24. Mayer, U., et al. 1997. Full blockade of intestinal P-glycoprotein and extensive inhibition of blood-brain barrier P-glycoprotein by oral treatment of mice with PSC833. J. Clin. Invest. 100:2430-2436.

25. Cordon-Cardo, C., et al. 1989. Multidrug-resistance gene (P-glycoprotein) is expressed by endothelial cells at blood-brain barrier sites. Proc Natl. Acad. Sci. USA. 86:695-698.

26. Wijnholds, J., et al. 1998. Multidrug resistance protein 1 protects the oropharyngeal mucosal layer and the testicular tubules against druginduced damage. J. Exp. Med. 188:797-808.

27. Flens, M.J., et al. 1996. Distribution of the multidrug resistance-associated protein (MRP) in normal and malignant human tissues. Am. J.
Pathol. 148:1237-1247.

28. Hipfner, D.R., Gauldie, S.D., Deeley, R.G., and Cole, S.P. 1994. Detection of the M(r) 190,000 multidrug resistance protein, MRP, with monoclonal antibodies. Cancer Res. 54:5788-5792.

29. Wright, S.R., et al. 1998. Immunohistochemical detection of multidrug resistance protein in human lung cancer and normal lung. Clin. Cancer Res. 4:2279-2289.

30. Mayer, R., et al. 1995. Expression of the MRP gene-encoded conjugate export pump in liver and its selective absence from the canalicular membrane in transport-deficient mutant hepatocytes. J. Cell Biol. 131:137-150.

31. Rao, V.V., et al. 1999. Choroid plexus epithelial expression of MDR1 P glycoprotein and multidrug resistance-associated protein contribute to the blood-cerebrospinal-fluid drug-permeability barrier. Proc. Natl. Acad. Sci. USA. 96:3900-3905.

32. Evers, R., et al. 1996. Basolateral localization and export activity of the human multidrug resistance-associated protein in polarized pig kidney cells. J. Clin. Invest. 97:1211-1218.

33. Rubin, L.L., and Staddon, J.M. 1999. The cell biology of the blood-brain barrier. Annu. Rev. Neurosci. 22:11-28.

34. Spector, R., and Johanson, C.E. 1989. The mammalian choroid plexus. Sci. Am. 261:68-74.

35. Mihorat, T.H. 1976. Structure and function of the choroid plexus and other sites of cerebrospinal fluid formation. Int. Rev. Cytol. 47:225-289. the organic anion transport protein in the brain. Proc. Natl. Acad. Sci. USA. 94:283-286.

37. Nishino, J., et al. 1999. Transepithelial transport of organic anions across the choroid plexus: possible involvement of organic anion transporter and multidrug resistance-associated protein. J. Pharmacol. Exp. Ther. 290:289-294.

38. Spector, R. 1989. Micronutrient homeostasis in mammalian brain and cerebrospinal fluid. J. Neurochem. 53:1667-1674.

39. Spector, R., and Goetzl, E.J. 1986. Leukotriene C4 transport and metabolism in the central nervous system. J. Neurochem. 46:1308-1312.

40. DiBenedetto, F.E., and Bito, L.Z. 1986. Transport of prostaglandins and other eicosanoids by the choroid plexus: its characterization and physiological significance. J. Neurochem. 46:1725-1731.

41. Spector, R., and Lorenzo, A.V. 1974. The effects of salicylate and probenecid on the cerebrospinal fluid transport of penicillin, aminosalicyclic acid and iodide. J. Pharmacol. Exp. Ther. 188:55-65.

42. Ogawa, M., Suzuki, H., Sawada, Y., Hanano, M., and Sugiyama, Y. 1994. Kinetics of active efflux via choroid plexus of beta-lactam antibiotics from the CSF into the circulation. Am. J. Physiol. 266:R392-R399.

43. Nohjoh, T., et al. 1989. Transport of cefodizime, a novel third generation cephalosporin antibiotic, in isolated rat choroid plexus. J. Pharmacol. Exp. Ther. 250:324-328.

44. Sawchuk, R.J., and Hedaya, M.A. 1990. Modeling the enhanced uptake of zidovudine (AZT) into cerebrospinal fluid. I. Effect of probenecid. Pharm. Res. 7:332-338.

45. Takasawa, K., Terasaki, T., Suzuki, H., and Sugiyama, Y. 1997. In vivo evidence for carrier-mediated efflux transport of 3 '-azido-3'-deoxythymidine and 2',3'-dideoxyinosine across the blood-brain barrier via a probenecidsensitive transport system. J. Pharmacol. Exp. Ther. 281:369-375.

46. Masereeuw, R., Jaehde, U., Langemeijer, M.W.E., de Boer, A.G., and Breimer, D.D. 1994. In vitro and in vivo transport of zidovudine (AZT) across the blood brain barrier and the effect of transport inhibitors. Pharm. Res. 11:324-330.

47. Kim, C.S., and Pritchard, J.B. 1993. Transport of 2,4,5-trichlorophenoxyacetic acid across the blood-cerebrospinal fluid barrier of the rabbit. J. Pharmacol. Exp. Ther. 267:751-757.

48. Burgio, D.E., Gosland, M.P., and McNamara, P.J. 1996. Modulation effects of cyclosporine on etoposide pharmacokinetics and CNS distribution in the rat utilizing microdialysis. Biochem. Pharmacol. 51:987-992.

49. Pérez-Urizar, J., Picazo, Y.F., Navarro-González, B., Flores-Murrieta, F.J., and Castañeda-Hernandez, G. 1996. A new, rapid, and economical highperformance liquid chromatographic assay with electrochemical detection for the determination of etoposide (VP-16) in human plasma samples. J. Liq. Chrom. \& Rel. Technol. 19:939-947.

50. Peng, K.-C., et al. 1999. Tissue and cell distribution of the multidrug resistance-associated protein (MRP) in mouse intestine and kidney. $J$. Histochem. Cytochem. 47:757-767.

51. Faucheron, J.L. 1999. Toxicity of non-steroidal anti-inflammatory drugs in the large bowel. Eur. J. Gastroenterol. Hepatol. 11:389-392.

52. Panwala, C.M., Jones, J.C., and Viney, J.L. 1998. A novel model of inflammatory bowel disease: mice deficient for the multiple drug resistance gene, Mdr1a, spontaneously develop colitis. J. Immunol. 161:5733-5744. 